\title{
Efeito do solo contaminado com óleo diesel na estrutura da raiz e da folha de plântulas de Sebastiania commersoniana (Euphorbiaceae) e Schinus terebinthifolius (Anacardiaceae)
}

Cleusa Bona ${ }^{1,3}$, Michella Yamamura Bardelli da Silva ${ }^{1}$, Igor Mendonça de Rezende ${ }^{1}$, Gedir de Oliveira Santos ${ }^{1}$, Luiz Antonio de Souza ${ }^{2}$ e Renata Charvet Inckot ${ }^{1}$

\begin{abstract}
RESUMO
(Efeito do solo contaminado com óleo diesel na estrutura da raiz e da folha de plântulas de Sebastiania commersoniana (Euphorbiaceae) e Schinus terebinthifolius (Anacardiaceae)). O objetivo deste trabalho foi avaliar se o solo com óleo diesel altera a estrutura da raiz e do eofilo de plântulas de S. commersoniana (Euphorbiaceae) e S. terebinthifolius (Anacardiaceae). Para cada espécie foram testados três tratamentos com solo contaminado e um solo controle, não contaminado. Os tratamentos diferiram pelo tempo entre a contaminação e a semeadura. S. commersoniana foi semeada 60, 120 e 210 dias e S. terebinthifolius 30, 90 e 180 dias após a contaminação. As amostras de raiz e eofilo foram coletadas 30 dias após a semeadura, fixadas e processadas segundo técnicas convencionais para anatomia vegetal e analisadas de forma qualitativa e quantitativa. Plântulas de S. commersoniana e S. terebinthifolius, em solo com óleo diesel, apresentaram alterações anatômicas na raiz e eofilo. O intervalo de tempo entre a contaminação e a semeadura interferiu na fitotoxicidade do solo. Isto é, quanto maior o intervalo de tempo entre a contaminação e a semeadura, menores foram as alterações anatômicas. As plântulas de S. terebinthifolius pareceram mais resistentes à contaminação por óleo diesel do que as de $S$. commersoniana.
\end{abstract}

Palavras-chave: anatomia, aroeira, Branquilho, hidrocarbonetos, poluição

\begin{abstract}
Effect of diesel contaminated soil on root and leaf of Sebastiania commersoniana (Euphorbiaceae) and Schinus terebinthifolius (Anacardiaceae)). The objective of this study was to evaluate whether the diesel contaminated soil alters the structure of the root and eophyll of $S$. commersoniana (Euphorbiaceae) and S. terebinthifolius (Anacardiaceae) seedlings. For each species three treatments with contaminated soil were tested, and compared to a control of uncontaminated soil. The treatments differed by the time between contaminations and sowing. S. commersoniana was sown 60, 120 and 210 days and S. terebinthifolius 30, 90 and 180 days after contamination. Samples of root and eophyll were collected 30 days after sowing and analyzed qualitatively and quantitatively. Seedlings of S. commersoniana and S. terebinthifolius, grown in diesel contaminated soil, had their root and eophyll anatomy modified. The time interval between contamination and sowing interferes with the soil phytotoxicityl. When greater the time interval between contamination and sowing lower were the anatomical changes. Seedlings of S. terebinthifolius seemed more resistant to contamination than those of $S$. commersoniana.
\end{abstract}

Key words: anatomy, aroeira, Branquilho, hydrocarbons, pollution

\section{Introdução}

Devido ao aumento na demanda de exploração de petróleo e seus derivados, acidentes envolvendo contaminação do ambiente por hidrocarbonetos de petróleo tornaramse frequentes nos últimos anos (Hutchinson et al. 2001). Dentre as contaminações ambientais ocorridas no Brasil destacam-se a contaminação da baía de Guanabara com cerca de seis milhões de litros de petróleo em 1975 (Libreria 2004); o derramamento de 4 milhões de litros de petróleo no município Araucária (PR), em 2000 (Ambicenter 2004); o afundamento da Plataforma de petróleo P-36, no Rio de Janeiro em 2001, que lançou aproximadamente 1,3 milhões de litros de petróleo (Libreria 2004); a contaminação com 48.000 L de óleo diesel que ocorreu em Morretes (PR), em 2001 (Sefloral 2001) e a contaminação do rio Guaecá, em

\footnotetext{
Universidade Federal do Paraná, Setor de Ciências Biológicas, Departamento de Botânica, Centro Politécnico, Curitiba, PR, Brasil

2 Universidade Estadual de Maringá, Departamento de Biologia, Maringá, PR, Brasil

3 Autor para correspondência: cleusabona@ufpr.br
} 
São Sebastião (SP) em 2004 (Eirós 2004). Esses derramamentos geram efeitos negativos na flora e fauna (Muratova et al. 2003) e a flora, geralmente, é a primeira a ser atingida (Malallah et al. 1996).

Os efeitos da contaminação variam de acordo com o tipo e a quantidade de óleo, a época do ano, o tipo de solo, a idade e espécie vegetal (Baker 1970; Pezeshki et al. 2000; Merkl et al. 2005; Kayode et al. 2009; Kisic et al. 2009). O contaminante pode ser absorvido pelas plantas (Bossert \& Bartha 1985; Alkio et al. 2005; Tan et al. 2005), além de alterar as propriedades do solo (Racine 1994; Li et al. 1997; Martinez \& López 2001; Roy et al. 2003; Chupakhina \& Maslennikov 2004; Peña-Castro et al. 2006). Solos com hidrocarbonetos têm tendência a reter menor quantidade de água (Roy et al. 2003; Peña-Castro et al. 2006), a apresentar menor disponibilidade de oxigênio (Pezeshki et al. 2000; Merkl et al. 2005) e de nutrientes (De Jong 1980). Entre os nutrientes menos disponíveis após contaminação do solo com hidrocarbonetos destaca-se o nitrogênio, um dos mais restritivos ao crescimento das plantas (Marschner 1995).

Além dos fatores abióticos, as plantas reagem de distintas maneiras à contaminação do solo por hidrocarbonetos. Embora a maioria dos trabalhos relate baixo desenvolvimento de plantas em solo contaminado (Racine 1994; Li et al. 1997; Adam \& Duncan 1999; Gill et al. 1992; Dorn \& Salanitro 2000; Chupakhina \& Maslennikov 2004; Merkl et al. 2005; Achuba 2006; White et al. 2006; Omosun et al. 2008; Farias et al. 2009), também há registros de maior comprimento radicial (Baker 1970) e até de recuperação da biomassa (Merkl et al. 2005). Alterações estruturais, como maior ramificação (Adam \& Duncan 1999), alterações no formato das células da raiz (Farias et al. 2009), redução das divisões celulares da raiz (Merkl et al. 2004; Achuba 2006), alteração da estrutura dos pêlos radiculares (Alkio et al. 2005), redução da área foliar, alteração na densidade estomática (Maranho et al. 2006; Omosun et al. 2008) e modificações no aspecto e espessura da cera epicuticular (Baker 1970; Omosun et al. 2008) foram registradas em diferentes espécies em solo contaminado.

Algumas espécies além de tolerar e crescer em solos com hidrocarbonetos (Ernest 1976; Quiñones-Aguilar et al. 2003; Pilon-Smits 2005), junto com os microrganismos associados à rizosfera, podem contribuir na descontaminação do solo (Cunnigham et al. 1996; Günther et al. 1996; Siciliano \& Germida 1999; Tesar et al. 2002; Singer et al. 2003), favorecendo a recomposição de áreas contaminadas. Para selecionar as espécies com potencial para a fitorremediação, é necessário primeiramente identificar espécies resistentes e compreender como essas reagem à contaminação. Portanto, a análise morfoanatômica pode revelar se a planta apresenta reações positivas ou negativas em relação ao estresse causado pelo contaminante no solo.

Sebastiania commersoniana (Euphorbiaceae) aparece como dominante, apresentando elevado Índice de Valor de Importância em estudos fitossociológicos realizados em flo- restas de galeria (Smith et al. 1988; Barddal et al. 2004). Devido à sua expressiva ocorrência nas planícies fluviais, essa espécie é estudada quanto a sua capacidade de adaptação a solos sujeitos à saturação hídrica plena (Kolb et al. 1998). Já Schinus terebinthifolius (Anacardiaceae) caracteriza-se pela ampla distribuição geográfica e pela alta plasticidade ecológica (Fleig \& Klein 1989), sendo utilizada nos reflorestamentos de áreas degradadas, inclusive mata ciliar, bem como no reposicionamento de dunas (Lorenzi 1992; Ferreti et al. 1995; Kageyama \& Gandara 2000; Fleig \& Klein 1989). Ambas as espécies crescem em terrenos secos e pobres em nutrientes, mas são também comuns em beira de córregos e em várzeas úmidas (Lorenzi 1992), sendo dessa forma importantes para a revegetação de áreas degradadas. Neste trabalho, é avaliado o possível efeito da contaminação do solo com óleo diesel sobre a estrutura anatômica da raiz e do eofilo, de plântulas de S. commersoniana e S. terebinthifolius.

\section{Material e métodos}

As sementes de Sebastiania commersoniana (Baill.) L. B. Sm. \& Downs (Euphorbiaceae) e frutos de Schinus terebinthifolius Raddi (Anacardiaceae) foram fornecidos pela Embrapa Florestas, Município de Colombo - Paraná. Para a viabilização das sementes de S. commersoniana, foi feita hidratação por aproximadamente 48 horas em câmara úmida. Enquanto que, os frutos de $S$. terebinthifolius foram reidratados e descascados, deixando as sementes prontas para a semeadura.

O solo do tipo gleissolo melânico, com textura argilosa (Fasolo et al. 2002) foi coletado no Município de Araucária - PR, onde ambas as espécies ocorrem naturalmente. Posteriormente, o solo foi seco, peneirado, homogeneizado e colocado em bandejas com aproximadamente $3 \mathrm{~kg}$ de solo seco. O solo foi umedecido com $50 \%$ de sua capacidade de retenção máxima (CRM), tomando por base os trabalhos de Muratova et al. (2003) e Li et al. (1997). A quantidade de óleo diesel por $\mathrm{kg}$ de solo foi definida pela quantidade máxima retida no solo previamente hidratado com $50 \%$ de sua CRM, sendo que o valor obtido foi de $92.4 \mathrm{~mL}$ de óleo diesel por kg de solo.

Para Sebastiania commersoniana a contaminação do solo foi realizada 60 (T60), 120 (T120) e 210 (T210) dias antes da semeadura e, para Schinus terebinthifolius, a contaminação foi feita 30 (T30), 90 (T90) e 180 (T180) dias antes da semeadura, além do tratamento controle (T0) sem contaminação, para ambas as espécies. A contaminação do solo foi realizada na mesma data para todos os tratamentos, porém a semeadura, devido ao atraso na maturação das sementes, ocorreu em períodos diferentes. Cada tratamento constou de cinco repetições (bandejas) com 50 sementes cada. O experimento foi conduzido em casa de vegetação, com aspersão de água (de 15 segundos a cada 1 hora), em temperatura ambiente (média de $22,8^{\circ} \mathrm{C}$ ).

Após 30 dias da semeadura, foram coletadas 10 plântulas de cada tratamento para obter amostras da raiz, a $1 \mathrm{~cm}$ do 
ápice, e do terço médio do eófilo. As amostras foram fixadas em FAA 50 (Johansen 1940) e processadas para inclusão em resina de hidroxietilmetacrilato. As secções foram obtidas em micrótomo de rotação (Leica RM $2145 \AA$ ), com espessura entre 5 a $7 \mu \mathrm{m}$ e coradas com azul de toluidina $0,05 \%$, pH 6,8 (O’Brien et al. 1965), azul de astra 1\% e safranina 1\% (Bukatsch 1972) e montadas em resina Permount ${ }^{\circ}$. Algumas secções foram submetidas a testes microquímicos com Lugol para detecção de amido (Foster 1949), Sudan III para detectar substâncias graxas (Sass 1951) e cloreto férrico para detectar a presença de compostos fenólicos (Johansen 1940).

Para análise em microscopia eletrônica de varredura (MEV) as amostras dos eofilos foram fixadas em FAA 50 e desidratadas em série etílica. Em seguida, o material foi desidratado via ponto crítico com $\mathrm{CO}_{2}$, em equipamento BAL-TEC CPD 030 - Critical Point Dryer. As amostras foram fixadas em suporte metálico com fita adesiva de cobre e posteriormente metalizadas com ouro em equipamento SCD 030 Balzers Union FL 9496 Balzers. As observações foram realizadas em Microscópio Eletrônico de Varredura Jeol JSM - 6360LV, no Centro de Microscopia Eletrônica da UFPR.

Para as análises quantitativas, mensurou-se o diâmetro total da raiz, porcentagem de área lacunar do córtex, diâmetro do raio do córtex, número de células no raio cortical, diâmetro do cilindro vascular da raiz e a espessura do eofilo. Foram feitas três mensurações por plântula em 10 plântulas por tratamento, para raiz e eofilo. As mensurações foram efetuadas em microscópio Olympus BX41TF com ocular micrometrada e o registro fotográfico no microscópio fotônico Zeiss Axiolab com câmera digital Sony P200. Para mensuração dos espaços intercelulares do córtex a imagem foi projetada com câmara clara e desenhada em papel. Essas imagens foram digitalizadas e analisadas no programa Sigma-Pro Versão 2.1. As análises estatísticas basearam-se na análise de variância (ANOVA), sendo determinado o DMS (Diferença Mínima Estatística) pelo teste de Tukey, a um nível de significância de 5\%. O programa estatístico utilizado foi o JUMP 5.0.1.

\section{Resultados}

O ápice radicial de Sebastiania commersoniana teve o meristema apical menos desenvolvido em solo contaminado, evidenciando uma zona meristemática mais curta (Fig. 1-2). Essa alteração foi mais marcante nas plântulas do tratamento T60. Nos tratamentos T120 e T210 o meristema apresentou estrutura semelhante às plantas do T0. As raízes em solo contaminado, principalmente no tratamento $\mathrm{T} 60$, apresentaram com frequência células epidérmicas e tecido subepidérmico rompidos e com células desestruturadas, o que não foi detectado nas plantas em solo não contaminado (Fig. 3-4). O ápice radicial de Schinus terebinthifolius não apresentou alterações morfoanatômicas evidentes.
A epiderme e camada subepidérmica da raiz de $S$. commersoniana e S. terebinthifolius não apresentaram alterações visíveis, em solo contaminado. Em todos os tratamentos aparecem células normais ou amassadas, e com ou sem compostos fenólicos (Fig. 5-8). O córtex radicial de S. commersoniana e de $S$. terebinthifolius, em solo contaminado, apresentou maior incidência de células rompidas, quando comparada às plantas do solo não contaminado (Fig. 5-8). A porcentagem de área lacunar no córtex, de ambas as espécies, foi maior em solo contaminado, principalmente nos tratamentos com contaminação mais recente (Tab. 1). $\mathrm{O}$ diâmetro e o número de células do raio do córtex foram maiores em ambas as espécies em solo contaminado (Tab. 2).

O cilindro vascular da raiz de $S$. commersoniana e $S$. terebinthifolius não apresentou alterações celulares, mas sim um adiantamento na maturação celular em solo contaminado. Isso se evidencia pelo maior desenvolvimento do cilindro vascular (Fig. 9-12), maior diâmetro total e do cilindro vascular da raiz de ambas as espécies em solo contaminado (Tab. 2).

A face adaxial da epiderme dos eofilos de S. commersoniana apresenta células de paredes anticlinais sinuosas com estrias epicuticulares finas e curtas (Fig. 13). Essa organização não é alterada nos tratamentos com contaminação (Fig. 14). A superfície da face abaxial é revestida por ceras epicuticulares em forma de cristas onduladas (Fig. 15). As ceras, em geral, parecem menos densas nos tratamentos com contaminação (Fig. 16) e ausentes na maior parte da superfície dos eofilos do tratamento T60 (Fig. 17 e 18).

Os eofilos de $S$. terebinthifolius apresentam células epidérmicas, na face adaxial, de formato irregular com paredes anticlinais sinuosas e cutícula estriada (Fig. 19). Em solo contaminado, essa mesma epiderme, geralmente possui áreas de células com formato alterado (Fig. 20). As células epidérmicas, da face abaxial, possuem cutícula pouco estriada, e estão presentes estômatos e tricomas glandulares (Fig. 21). Em todos os tratamentos com solo contaminado, a face abaxial também apresentou áreas com células epidérmicas com formato alterado e sem estrias epicuticulares (Fig. 22-24).

Tanto as células epidérmicas quanto as do mesofilo dos eofilos de S. commersoniana encontravam-se completamente diferenciadas no tratamento T0 (Fig. 25), enquanto que nos tratamentos com solo contaminado essas mesmas células estavam em estágio menos desenvolvido, com células menores, conteúdo mais denso e espaços intercelulares menores (Fig. 26-28). A espessura dos eofilos de $S$. commersoniana foi menor em solo contaminado (Tab. 3).

No eofilo de S. terebinthifolius não foram constatadas diferenças qualitativas evidentes, em secção transversal, entre as células epidérmicas das plantas do T0 e as dos tratamentos com solo contaminado. Por outro lado, as células do mesofilo das plantas em solo contaminado, principalmente nos tratamentos T30 e T90, apresentaram reação mais intensa para compostos fenólicos, em relação aos demais 

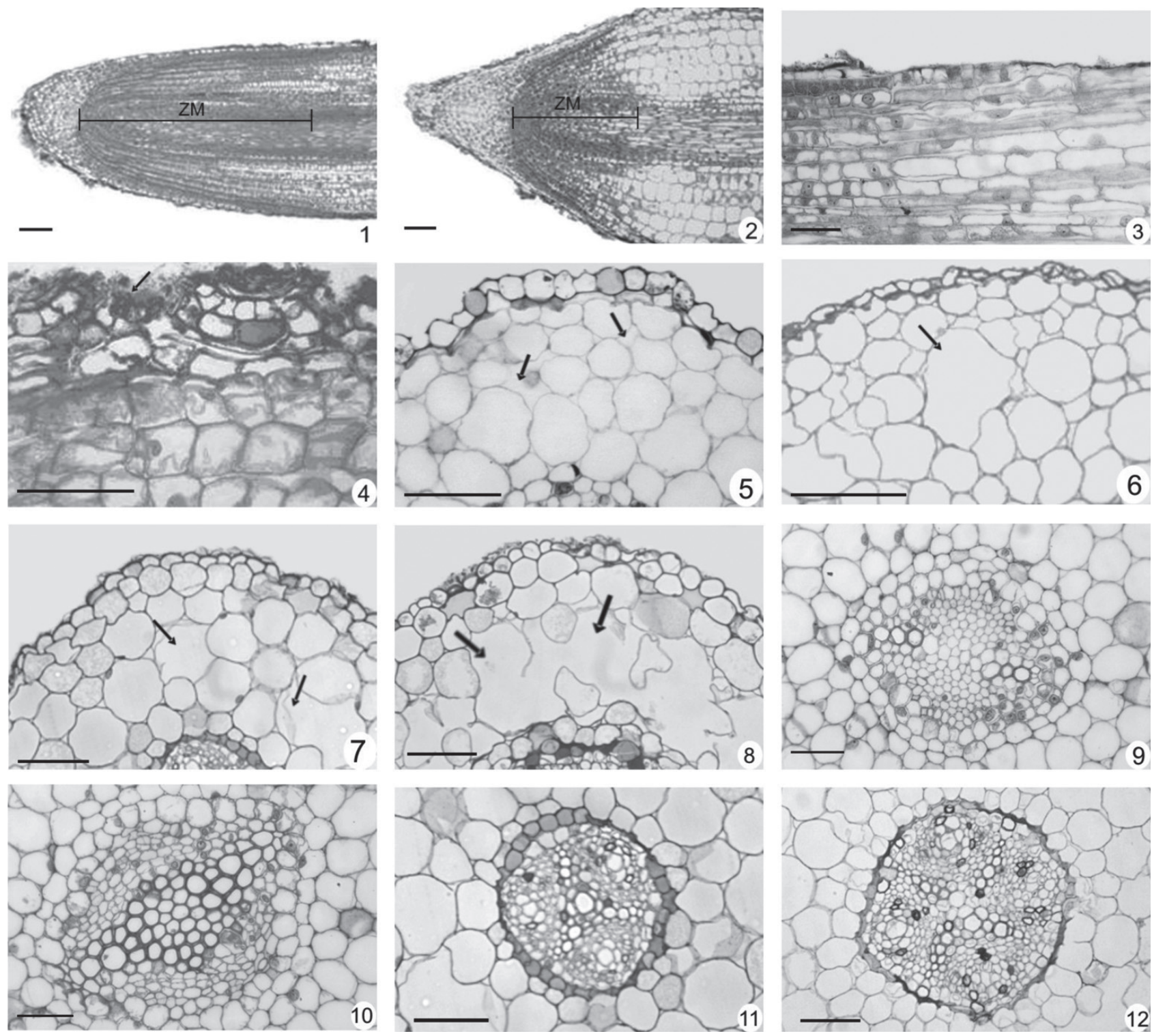

Figuras 1-12. Raiz. 1-6, 9-10. Sebastiania commersoniana (Baill.) L. B. Sm. \& Downs. 7-8, 11-12. Schinus terebinthifolius Raddi. 1. Ápice em secção longitudinal, T0. 2. Ápice em secção longitudinal, T60. 3. Secção longitudinal, T0. 4. Secção longitudinal evidenciando rompimento dos tecidos (seta), T60. 5-6. Secções transversais mostrando epiderme e córtex, T0 (5) e T60 (6), com áreas lacunares (setas). 7-8. Secções transversais evidenciando epiderme, córtex com lacunas T0 (7) e T30 (8). 9-10- Secções transversais mostrando o cilindro vascular, T0 (9) e T60 (10). 11-12. Secções transversais mostrando o cilindro vascular, T0 (11) e T30 (12). ZM = zona meristemática. Barra $=50 \mu \mathrm{m}$.

tratamentos. A espessura do eofilo foi semelhante em todos os tratamentos (Tab. 3), no entanto parece haver um ligeiro atraso na diferenciação celular (Fig. 19-32).

A nervura central do eofilo de $S$. commersoniana apresenta células completamente diferenciadas no tratamento T0 e células em diferenciação nas plantas em solo contaminado, sendo mais evidente essa característica, no tratamento T60, onde se verifica menor vacuolização das células do parênquima paliçádico e menor desenvolvimento dos tecidos vasculares (Fig. 33-34). Em S. terebinthifolius, a alteração mais marcante na nervura central é a reação mais intensa para compostos fenólicos na endoderme das plantas em solo contaminado (Fig. 35-36).

\section{Discussão}

A redução da região meristemática no ápice da raiz, em solo contaminado, também foi registrada por Inckot et al. (2008). Esses autores relataram que quanto maior o teor de hidrocarbonetos no solo, menor foi a região meristemática na raiz de Mimosa pilulifera Benth. Achuba (2006) constatou que a concentração do óleo no solo está diretamente relacionada à redução no tamanho e divisão celular no meristema radicial de Vigna unguiculata (L.) Walp. A menor região meristemática da raiz de $S$. commersoniana, em solo contaminado, se deve a diferenciação mais rápida das células. Essa capacidade pode ser um dos fatores que contribui 
Efeito do solo contaminado com óleo diesel na estrutura da raiz e da folha de plântulas de Sebastiania commersoniana (Euphorbiaceae)...

Tabela 1. Porcentagem de área lacunar do córtex da raiz a $1 \mathrm{~cm}$ do ápice de Sebastiania commersoniana em solo contaminado 60 (T60), 120 (T120), 210 (T210) dias antes da semeadura e de Schinus terebinthifolius em solo contaminado 30 (T30), 90 (T90), 180 (T180) dias antes da semeadura e em solo não contaminado (T0). $\mathrm{n}=10$.

\begin{tabular}{cccccccc}
\hline & \multicolumn{3}{c}{ Sebastiania commersoniana } & \multicolumn{3}{c}{ Schinus terebinthifolius } \\
\hline T60 & T120 & T210 & T0 & T30 & T90 & T180 & T0 \\
$21 \%$ & $22 \%$ & $12 \%$ & $10 \%$ & $45 \%$ & $24 \%$ & $21 \%$ & $4 \%$ \\
\hline
\end{tabular}
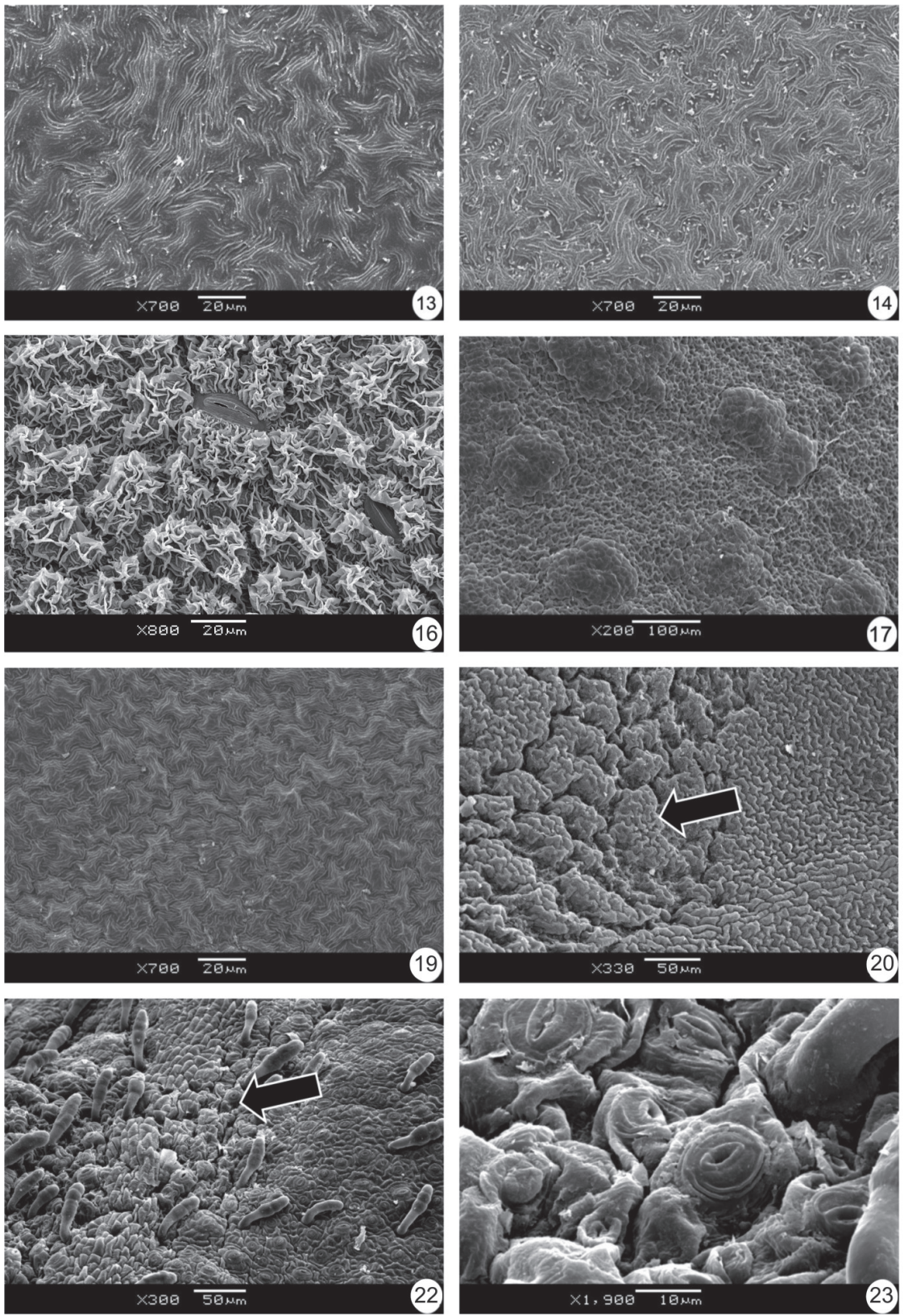
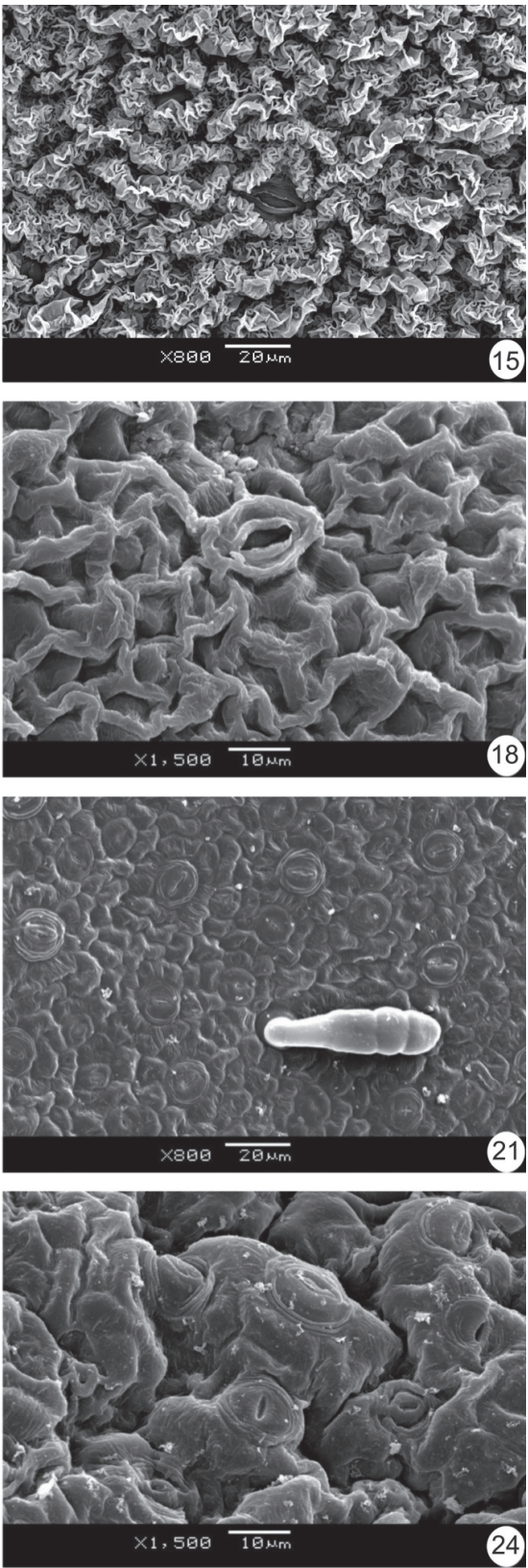

Figuras 13-24. Superfície do eofilo em microscopia eletrônica de varredura (MEV). 13-18. Sebastiania commersoniana (Baill.) L. B. Sm. \& Downs. 13. Face adaxial, tratamento T0. 14. Face adaxial, tratamento T60. 15. Face abaxial, tratamento T0. 16. Face abaxial, tratamento T60. 17. Face abaxial, tratamento T60. 18. Detalhe da figura anterior. 19-24. Schinus terebinthifolius Raddi. 19. Face adaxial, tratamento T0. 20. Face adaxial, área com células alteradas (seta), tratamento T180. 21. Face abaxial, tratamento T0. 22. Face abaxial, tratamento T30, áreas com células alteradas (seta). 23. Detalhe da figura anterior. 24. Face abaxial, tratamento T180 com células alteradas. 
Tabela 2. Diâmetro total $(\mu \mathrm{m})$, raio do córtex $(\mu \mathrm{m})$, diâmetro do cilindro vascular $(\mu \mathrm{m})$ e número de camadas de células do córtex da raiz, a $1 \mathrm{~cm}$ do ápice, de Sebastiania commersoniana (Baill.) L. B. Sm. \& Downs em solo contaminado 60 (T60), 120 (T120), 210 (T210) dias antes da semeadura e de Schinus terebinthifolius Raddi em solo contaminado 30 (T30), 90 (T90), 180 (T180) dias antes da semeadura e em solo não contaminado (T0). (n=10; média \pm desvio padrão. As médias seguidas da mesma letra não são significativamente diferentes baseadas pelo teste de Tukey p $<0,05$ ).

\begin{tabular}{|c|c|c|c|c|c|c|c|c|}
\hline & \multicolumn{4}{|c|}{ Sebastiania commersoniana } & \multicolumn{4}{|c|}{ Schinus terebinthifolius } \\
\hline & T60 & T120 & $\mathrm{T} 210$ & T0 & $\mathrm{T} 30$ & T90 & T180 & T0 \\
\hline Diâmetro total $(\mu \mathrm{m})$ & $\begin{array}{l}909,6^{\text {a }} \\
\pm 120,4\end{array}$ & $\begin{array}{l}784,7^{\text {b }} \\
\pm 70,7\end{array}$ & $\begin{array}{r}877^{\mathrm{a}, \mathrm{b}} \\
\pm 178,5\end{array}$ & $\begin{array}{l}646,6^{\mathrm{c}} \\
\pm 60,8\end{array}$ & $477,5^{a} \pm 51,50$ & $463,1^{\mathrm{a}} \pm 40,17$ & $357,6^{\mathrm{b}} \pm 56,76$ & $330,9^{b} \pm 54,06$ \\
\hline Raio do córtex $(\mu \mathrm{m})$ & $\begin{array}{l}302^{\text {a }} \\
\pm 52,4\end{array}$ & $\begin{array}{l}247,2^{a, b} \\
\pm 41\end{array}$ & $\begin{array}{l}290,5^{\text {a }} \\
\pm 82,7\end{array}$ & $\begin{array}{l}208,8^{\text {b }} \\
\pm 24,93\end{array}$ & $177,4^{\mathrm{a}} \pm 22,90$ & $\begin{array}{l}167,3 \text { a,b } \\
\pm 22,31\end{array}$ & $127,3^{\mathrm{b}} \pm 24,92$ & $124,3^{b} \pm 25,26$ \\
\hline $\begin{array}{l}\text { Diâmetro do cilindro } \\
\text { vascular }(\mu \mathrm{m})\end{array}$ & $\begin{array}{l}293^{\text {a }} \\
\pm 32,4\end{array}$ & $\begin{array}{c}256,5^{\mathrm{b}} \\
\pm 18\end{array}$ & $\begin{array}{c}265,6^{\mathrm{a}, \mathrm{b}} \\
\pm 32,3\end{array}$ & $\begin{array}{l}206,4^{\mathrm{c}} \\
\pm 12,9\end{array}$ & $\begin{array}{l}160,9 \text { a, } \\
\pm 23,77\end{array}$ & $183^{\mathrm{a}} \pm 23,23$ & $129,2^{b} \pm 31,93$ & $122,9^{b} \pm 28,94$ \\
\hline $\begin{array}{l}\text { Número de camadas } \\
\text { de células do córtex }\end{array}$ & $\begin{array}{l}7,7^{\mathrm{a}} \\
\pm 0,4\end{array}$ & $\begin{array}{r}7,5^{\mathrm{a}} \\
\pm 0,5\end{array}$ & $\begin{array}{l}7,4^{\mathrm{a}} \\
\pm 0,9\end{array}$ & $\begin{array}{l}5,2^{\mathrm{b}} \\
\pm 0,9\end{array}$ & $\begin{array}{c}5^{\mathrm{a}} \\
\pm 0,4\end{array}$ & $\begin{array}{c}5^{\mathrm{a}} \\
\pm 0,9\end{array}$ & $\begin{array}{l}4,4^{\mathrm{ab}} \\
\pm 1,0\end{array}$ & $\begin{array}{c}4^{\mathrm{b}} \\
\pm 0,6\end{array}$ \\
\hline
\end{tabular}

Tabela 3. Espessura do eofilo ( $\mu \mathrm{m})$ de Sebastiania commersoniana (Baill.) L. B. Sm. \& Downs. em solo contaminado 60 (T60), 120 (T120), 210 (T210) dias antes da semeadura e de Schinus terebinthifolius Raddi. em solo contaminado 30 (T30), 90 (T90), 180 (T180) dias antes da semeadura e em solo não contaminado (T0). (n=10; média \pm desvio padrão. As médias seguidas da mesma letra não são significativamente diferentes baseadas pelo teste de Tukey $\mathrm{p}<0,05)$.

\begin{tabular}{cccccccc}
\hline & \multicolumn{3}{c}{ Sebastiania commersoniana } & \multicolumn{3}{c}{ Schinus terebinthifolius } \\
\hline T60 & T120 & T210 & T0 & T30 & T90 & T180 & T0 \\
$118,19^{\mathrm{b}}$ & $127,11^{\mathrm{b}}$ & $118,93^{\mathrm{b}}$ & $150,9^{\mathrm{a}}$ & $110,1^{\mathrm{a}}$ & $107,9^{\mathrm{a}}$ & $108,4^{\mathrm{a}}$ & $111,7^{\mathrm{a}}$ \\
$\pm 8,92$ & $\pm 4,46$ & $\pm 3,41$ & $\pm 5,61$ & $\pm 10,42$ & $\pm 6,77$ & $\pm 8,61$ & $\pm 7,50$ \\
\hline
\end{tabular}

para a resistência dessa espécie quando sob estresse em solo contaminado. Também indica redução do estresse com o passar do tempo, pois nos tratamentos T120 e T210 o meristema apresentou estrutura semelhante às plantas do T0. A diferenciação mais rápida das células também foi relatada para outras condições de estresse. Segundo Marcondes \& Garcia (2009), em plantas sob condições de estresse salino, alterações fisiológicas poderiam levar a ativação precoce de genes envolvidos na diferenciação celular. E, ainda segundo esses autores as alterações ao nível de diferenciação celular são alterações que favorecem o desenvolvimento da planta na condição de estresse.

Ao contrário do que foi observado em S. commersoniana, as raízes de $S$. terebinthifolius, em solo com óleo diesel, não apresentaram alterações no meristema e nas células epidérmicas. Esse fato evidencia que a resposta à contaminação do solo diferiu entre as espécies, e que S. terebinthifolius, parece mais resistente ao solo contaminado. Alterações, na epiderme da raiz em solo contaminado, também foram registradas para Erythrina crista-galli L., que apresentou células dispostas de maneira desorganizada (Farias et al. 2009). No entanto, esses autores não relataram rompimento dessas células, o que foi evidenciado em $S$. commersoniana. Esses rompimentos podem facilitar a penetração do óleo nos tecidos internos, todavia, se faz necessário análises mais específicas, como cromatografia gasosa e espectrometria com fluorescência (Alkio et al. 2005), para detectar a presença do contaminante no interior do órgão (Alkio et al. 2005; Tan et al. 2005).

O aumento no raio do córtex das raízes em solo contaminado, para ambas as espécies, se deveu tanto ao aumento no número de células, quanto ao aumento na porcentagem de espaços intercelulares. No entanto em S. commersoniana é mais evidente o aumento no número de células enquanto que em S. terebinthifolius os espaços intercelulares são mais proeminentes. $\mathrm{O}$ aumento nos espaços intercelulares do córtex de raízes em solo contaminado também foi registrado em Spartina alterniflora Loisel., Sagittaria lancifolia L. e Erythrina crista-galli (Pezeshki et al. 2000; Farias et al. 2009). A formação de aerênquima pode reduzir o estresse hídrico (Levitt 1980) e o ambiente anóxico (Sifton 1945) provocados pela presença de hidrocarbonetos no solo (Baker 1970). Além disso, algumas espécies podem res- 


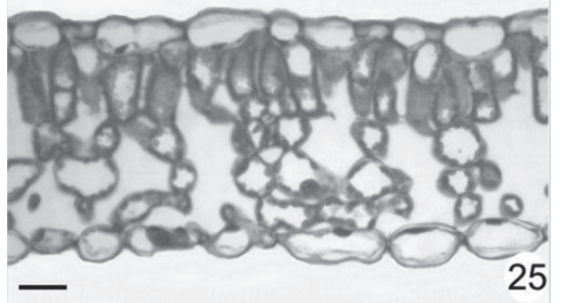

25

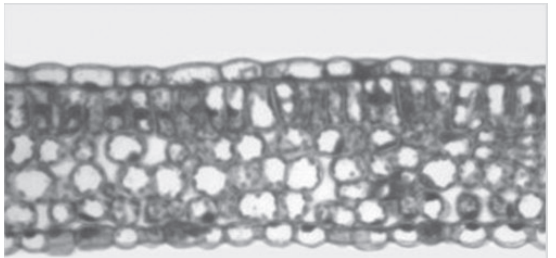

28

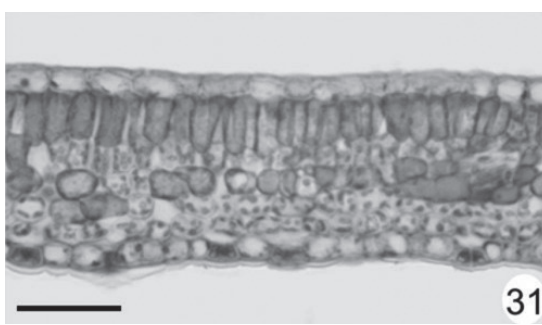

31

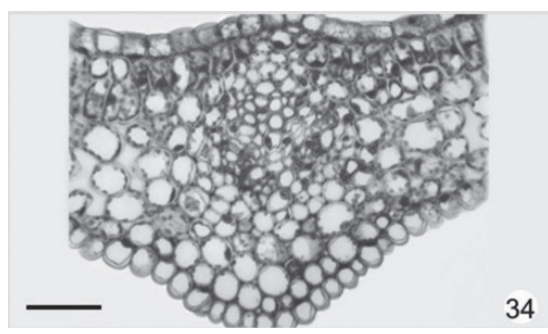

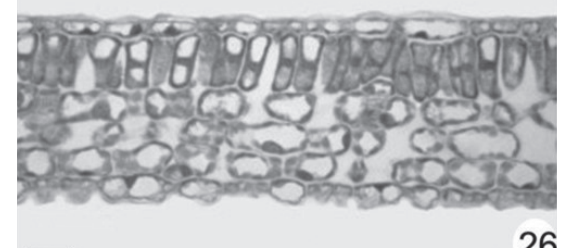

26
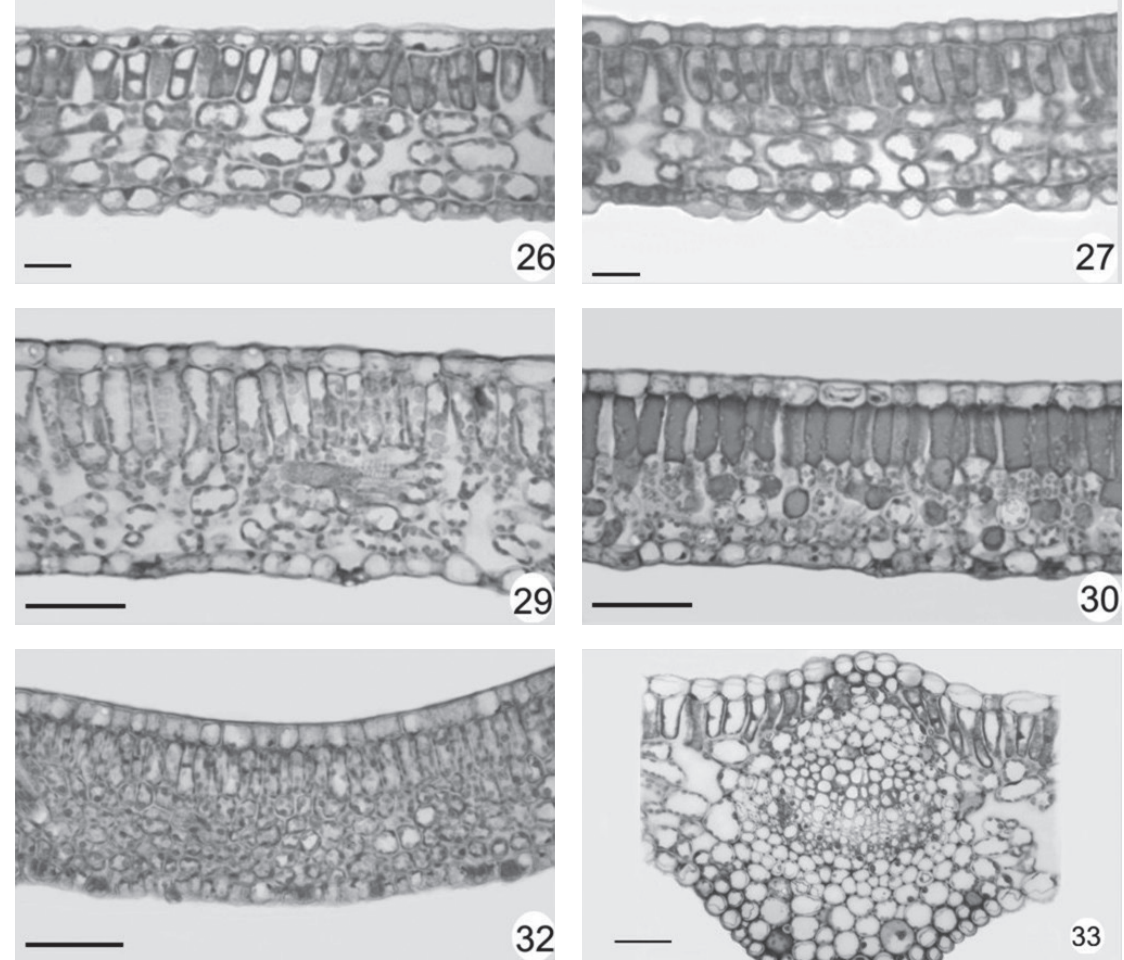

32
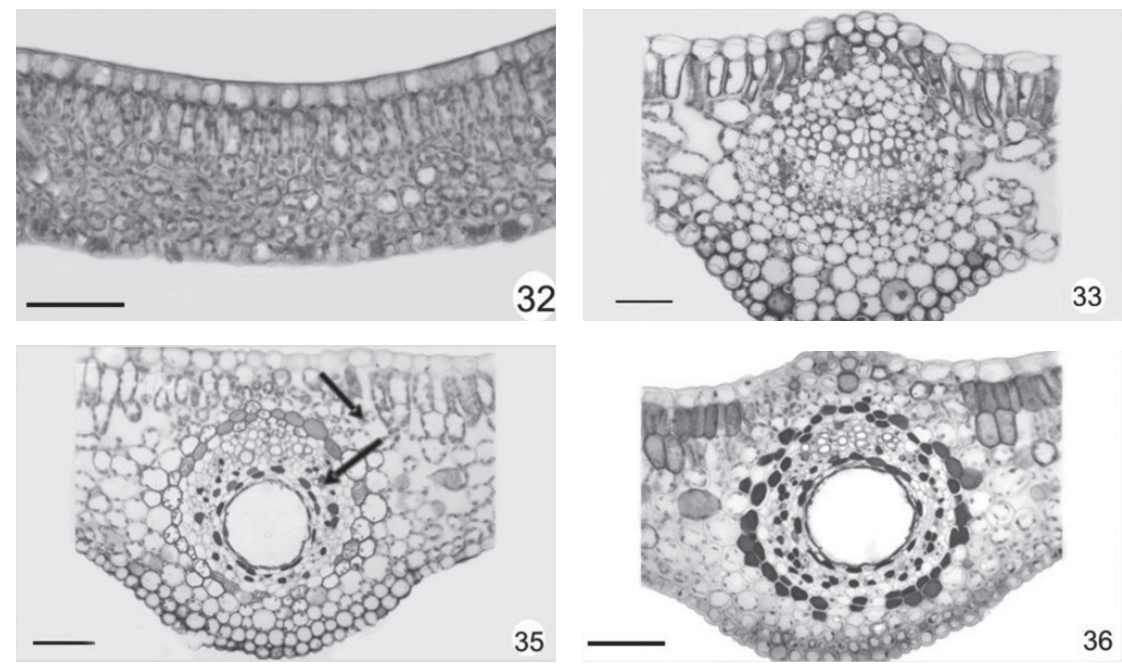

36

Figuras 25-36. Limbo do eofilo em secção transversal. 25-32: Epiderme e mesofilo. 33-36: Nervura central. 25-28, 33-34: Sebastiania commersoniana (Baill.) L. B. Sm. \& Downs. 29-32, 35-36: Schinus terebinthifolius Raddi. 25. Tratamento T0. 26. Tratamento T210. 27. Tratamento T120, 28. Tratamento T60. 29. Tratamento T0. 30. Tratamento T180. 31. Tratamento T90. 32. Tratamento T30. 33. Tratamento T0. 34. Tratamento T60. 35. Tratamento T0. 36. Tratamento T30. Barra $=50 \mu \mathrm{m}$.

ponder a deficiência hídrica aumentando o diâmetro das raízes e simultaneamente reduzindo o crescimento (Merkl et al. 2004). Contudo, há espécies, sob a influência do solo contaminado por óleo, que não apresentaram alteração no diâmetro das raízes (Merkl et al. 2005; Inckot et al. 2008). Outras, no entanto, como Chromolaena odorata (L.) R.M. King \& H. Rob. e Amaranthus hybridus L. apresentaram deformação celular nas camadas corticais (Gill et al. 1992; Omosun et al. 2008) e redução no tamanho das células e dos espaços intercelulares (Omosun et al. 2008). A redução do parênquima cortical de $A$. hybridus foi atribuída a uma condição inicial de seca fisiológica (Omosun et al. 2008). Desse modo, a maior porcentagem de espaços intercelulares tanto de S. commersoniana quanto de S. terebinthifolius, em solo contaminado, indica uma provável redução de oxigênio nesses solos e evidencia a capacidade dessas espécies em formar aerênquima.
O maior diâmetro do cilindro vascular e início de formação de tecidos secundários, a $1 \mathrm{~cm}$ do ápice, nas raízes em solo contaminado, evidencia diferenciação precoce do tecido vascular. Essa diferenciação é mais evidente em $S$. commersoniana, cujo ápice radicial foi mais afetado. Resultados similares foram registrados para $M$. pilulifera em solo com petróleo (Inckot et al. 2008) e em Zea mays L., sob estresse salino (Azaizeh \& Steudle 1991).

As alterações estruturais na superfície dos eofilos de $S$. commersoniana e de S. terebinthifolius, em solo contaminado, foram mais aparentes nos tratamentos recém contaminados. Além disso, na face abaxial desses eofilos, as alterações foram mais intensas, o que deve estar relacionado à presença de compostos voláteis no óleo diesel, como descrito por Adam \& Duncan (2002). As alterações anatômicas nas folhas de espécies expostas a contaminação por hidrocarbonetos podem ser variáveis. Folhas de Arabidopsis thaliana (L.) 
Heynh., em solo com fenantreno (hidrocarboneto oriundo do petróleo) apresentaram lesões e necroses (Alkio et al. 2005); Amaranthus hybridus teve alteração no formato das células epidérmicas, paredes mais sinuosas e cutícula mais espessa em solo contaminado com óleo cru (Omosum et al. 2008). Segundo Omosum et al. (2008) essas alterações estão relacionadas as condições de seca fisiológica, provocadas pelo contaminante. Por outro lado, Mimosa pilulifera não apresentou alterações estruturais nos cotilédones e eofilo quando exposta a um solo contaminado com petróleo há cinco anos (Inckot et al. 2008).

A menor espessura do eofilo em $S$. commersoniana, em solo contaminado, é resultado do atraso na maturação dos tecidos, no momento da coleta (30 dias após a semeadura), pois a completa expansão desses ocorreu tardiamente em relação às plantas do solo não contaminado. Notou-se também que o efeito sobre a anatomia das folhas de $S$. commersoniana foi mais intenso nos tratamentos com contaminação mais recente. Por outro lado, esse resultado não foi tão evidente em $S$. terebinthifolius, onde os eofilos estavam num estágio semelhante de desenvolvimento e não apresentaram diferença estatística na espessura entre os tratamentos. A resposta de $S$. commersoniana evidencia a redução dos efeitos da contaminação do solo com óleo diesel ao longo do tempo e a maior sensibilidade dessa espécie, ao efeito da contaminação, em relação a $S$. terebinthifolius.

Apesar da presença de fenóis ser comum em Anacardiaceae (Harbone \& Baxter 1995), acredita-se que a presença mais marcante de compostos fenólicos em S. terebinthifolius, em solo contaminado, esteja relacionada a resistência ao contaminante, como registrado por Malallah et al. (1998). Estes autores registraram redução da quantidade de compostos fenólicos em espécies crescendo em solo com petróleo e concluiram que o baixo nível de fenóis pode ter contribuído para diminuir a resistência das plantas em relação aos PAHs (Hidrocarbonetos aromáticos do petróleo) no ambiente. Os resultados encontrados neste trabalho, provavelmente indicam que a presença de compostos fenólicos pode aumentar a resistência da planta ao ambiente contaminado com hidrocarbonetos, como registrado para S. terebinthifolius. Também se pode concluir que a contaminação mais recente provoca um maior grau de estresse, visto que nos tratamentos com solo recém contaminado, S. terebinthifolius apresentou a reação mais intensa para compostos fenólicos.

\section{Conclusão}

Plântulas de Sebastiania commersoniana e Schinus terebinthifolius, em solo contaminado por óleo diesel, sofreram alterações morfoanatômicas na raiz e eofilo. O intervalo de tempo entre a contaminação e a semeadura interferiu no grau de alteração celular das plântulas. Isto é, quanto maior o intervalo de tempo, entre a contaminação e a semeadura, menores foram as alterações anatômicas. As plântulas de $S$. terebinthifolius foram mais resistentes à contaminação do solo por óleo diesel do que às de S. commersoniana, pois não sofreram alterações no ápice radicial, no desenvolvimento dos eofilos e apresentaram reação mais intensa para compostos fenólicos.

\section{Agradecimentos}

A Embrapa Florestas pelo fornecimento das sementes e ao Centro de Microscopia Eletrônica da Universidade Federal do Paraná pelo processamento e análise em microscopia eletrônica de varredura. Agradecemos também a professora Marguerite Quoirin, da Universidade Federal do Paraná pela colaboração.

\section{Referências}

Achuba, F.I. 2006. The effect of sublethal concentrations of crude oil on the growth and metabolism of Cowpea (Vigna unguiculata) seedlings. The Environmentalist 26: 17-20.

Adam, G. \& Duncan, H.J. 1999. Effect of diesel fuel on growth of selected plant species. Environment Geochemistry and Health 21: 353-357.

Adam, G. \& Duncan, H.J. 2002. Influence of diesel fuel on seed germination. Environmental Pollution 120: 363-370.

Alkio, M.; Tabuchi, T.M.; Wang, X. \& Colón-Carmona, A. 2005. Stress responses to polycyclic aromatic hydrocarbons in Arabidopsis include growth inhibition and hypersensitive response-like symptoms. Journal of Experimental Botany 56: 2983-2994.

Ambicenter. 2004. <http://www.ambicenter.com.br/petrobras.htm.>

Azaizeh, H. \& Steudle, E. 1991. Effects of salinity on water transport of excised maize (Zea mays L.) roots. Plant Physiology 97: 1136-1145.

Baker, J.M. 1970. The effects of oils on plants. Environmental Pollution 1: $27-44$.

Barddal, M.L.; Roderjan, C.V.; Galvão, F. \& Curcio, G.R. 2004. Caracterização florística e fitossociológica de um trecho sazonalmente inundável de floresta aluvial, em Araucária, PR. Ciência Florestal 14: $37-50$

Bossert, I. \& Bartha, R. 1985. Plant growth on soil with a history of oil sludge disposal. Soil Science 140: 75-77.

Bukatsch, F. 1972. Bemerkungen zur doppelfärbung astrablau-safranin. Mikrokosmos 61: 33-36.

Chupakhina, G.N. \& Maslennikov, P.V. 2004. Plant adaptation to oil stress. Russian Journal of Ecology 35: 290-295.

Cunnigham, S.D.; Anderson, T.A.; Schwab, P.A. \& Hsu, F.C. 1996 Phytoremediation of soils contaminated with organic pollutants. Advances in Agronomy 6: 55-114.

De Jong, E. 1980. The effect of a crude oil spill on cereals. Environmental Pollution 22: 187-196.

Dorn, P.B. \& Salanitro, J.P. 2000. Temporal ecological assessment of oil contamined soils before and after bioremediation. Chemosphere 40: 419-426.

Eirós, M. 2004. Vazamento deixa praia de Guaecá (SP) imprópria. <http:// www1.folha.uol.com.br/folha/cotidiano/ult95u90304.shtml>

Ernest, W.H.O. 1976. Effects of air pollutants on plants. Cambridge, Cambridge University Press.

Farias, V.; Maranho, L.T.; Vasconcelos, E.C.; Filho, M.A.S.; Lacerda, L.G.; Azevedo, J.A.M.; Pandey, A. \& Soccol, C.R. 2009. Phytodegradation potential of Erythrina crista-galli L., Fabaceae, in petroleumcontamined soil. Applied Biochemistry Biotechnology 157: 10-22.

Fasolo, P.J.; Bognola, I.A.; Carvalho, A.P.; Potter, R.O \& Bhering, S.B. 2002. Levantamento de reconhecimento dos solos da região sudeste do Estado do Paraná (área 4, 5 e 6). Boletim de Pesquisa e Desenvolvimento 13: 1-142. 
Ferreti, A.R.; Kageyama, P.Y.; Arboez, G.; Santos, J.D.; Barros, M.; Lorza, R.F. \& Oliveira, C. 1995. Classificação das espécies arbóreas em grupos ecológicos para revegetação com nativas no Estado de São Paulo. Forestar Estatístico 3: 2-6.

Fleig, M. \& Klein, R.M. 1989. Anacardiáceas. In: Flora Ilustrada Catarinense. Herbário Barbosa Rodrigues. Itajaí, R. Reitz.

Foster, A.S. 1949. Practical anatomy. New York, New York Press.

Gill, L.S.; Nyawuame, H.G.K. \& Ehikhametalor, A.O. 1992. Effect of crude oil on the growth and anatomical features of Chromolaena odorata (L.) K. \& R. Newsletter 6: 1-6.

Günther, T.; Dornberger, U. \& Fritsche, W. 1996. Effects of ryegrass on biodegradation of hydrocarbons in soil. Chemosphere 33: 203-215.

Harbone, J.B. \& Baxter, H. 1995. Phytochemical dictionary: a handbook of bioactive compounds from plants. London, Taylor \& Francis.

Hutchinson, S.L.; Banks, M.K.; Schwab, A.P. 2001. Phytoremediation of age petroleum sludge: effects of inorganic fertilizer. Journal of Environmental Quality 30: 395-403.

Inckot, R.C.; Bona, C.; Souza, A.L. \& Santos, G.O. 2008. Anatomia das plântulas de Mimosa pilulifera (Leguminosae) crescendo em solo contaminado com petróleo e solo biorremediado. Rodriguésia 59: 513-524.

Johansen, D.A. 1940. Plant microtechnique. New York, McGraw-Hill Book.

Kageyama, P. \& Gandara, F.P. 2000. Revegetação de áreas ciliares. São Paulo, Editora da Universidade de São Paulo.

Kayode, J.; Olowoyo, O. \& Oyedeji, A. 2009. The effects of used engine oil pollution on the growth and early seedling performance of Vigna uniguiculata and Zea mays. Research Journal of Soil Biology 1: 15-19.

Kisic, I.; Mesic, S.; Basic, F.; Brkic, V.; Mesic, M.; Durn, G.; Zgorelec, Z. \& Bertovic, L. 2009. The effect of drilling fluids and crude oil on some chemical characteristics of soil and crops. Geoderma 149: 209-216.

Kolb, R.M.; Medri, M.E.; Bianchini, E.; Pimenta, J.A.; Giloni, P.C. \& Correa G.T. 1998. Anatomia ecológica de Sebastiania commersoniana (Baillon) Smith \& Downs (Euphorbiaceae) submetida ao alagamento. Revista Brasileira de Botânica 21: 305-312.

Levitt, J. 1980. Responses of plants to environmental stress: water, radiation, salt and other stresses. New York, Academic Press.

Li, X.; Feng, Y. \& Sawatsky, N. 1997. Importance of soil-water relations in assessing the endpoint of biorremediated soils. Plant and Soil 192: 219-226.

Libreria. 2004. Disponível em: <http://www.libreria.com.br/portal/artigos/ ambiente/pol_mares/05.shtml.

Lorenzi, H. 1992. Árvores Brasileiras: Manual de Identificação e Cultivo de Plantas Arbóreas Nativas do Brasil. São Paulo, Plantarum.

Malallah, G.; Afzal, M.; Gulshan, S.; Kurian, M. \& Dhami, M.S.I. 1996. Vicia faba as a bioindicator of oil pollution. Environmental Pollution 92: 213-217.

Malallah, G.; Afzal, M.; Kurian, M.; Gulshan, S. \& Dhami, M.S.I. 1998. Impact of oil pollution on some desert plants. Environment International 24: 919-924.

Maranho, L.T.; Galvão, F.; Preussler, K.H.; Muñiz, G. \& Kuniyoshi, Y.S. 2006. Efeitos da poluição por petróleo na estrutura da folha de Podocarpus lambertii KLotzsch ex Endll., Podocarpaceae. Acta Botanica Brasilica 20: 615-624.

Marcondes, J. \& Garcia, A.B. 2009. Aspectos citomorfológicos do estresse salino em plântulas de arroz (Oryza sativa L.). Arquivos do Instituto de Biologia 76: 187-194.

Marschner, H. 1995. Mineral nutrition on higher plants. London, Academic Press.
Martinez, V.E. \& López. M.F. 2001. Efecto de hidrocarbonus em lãs propriedades físicas y químicas de suelo argiloso. Terra 19: 9-16.

Merkl, N.; Schultze-Kraft, R. \& Infante, C. 2004. Phytoremediation in tropics- the effect of crude oil on the growth on tropical plants. Biorremediation Journal 8: 177-184

Merkl, N.; Schultze-Kraft, R. \& Infante. C. 2005. Phytoremediation in the tropics - influence of heavy crude oil on root morphological characteristics of graminoids. Environmental Pollution 138: 86-91.

Muratova, A.Y.; Turkovskaya, O.V.; Hübner, T.E. \& Kuschk, P. 2003. Studies of the efficacy of Alfalfa and Reed in the phytoremediation of hydrocarbon-polluted soil. Applied Biochemistry and Microbiology 39: 681-688.

O'Brien, T.P.; Feder, N. \& McCully, M.E. 1965. Polychromatic staining of plant cell walls by toluidine blue O. Protoplasma 59: 368-373 .

Omosun, G.; Markson, A.A. \& Mbanasor, O. 2008. Growth and anatomy of Amaranthus Hybridus as affected by different crude oil concentrations. American-Eurasian Journal of Scientific Research 3: 70-74.

Peña-Castro, J.M.; Barrera-Figueroa, E.B.; Fernández-Linares, L. \& Ruizmedrano, R. 2006. Isolation and identification of up-regulate genes in bermudagrass roots (Cynodon dactylon L.) grown under petroleum hydrocarbon stress. Plant Science 170: 724-731.

Pezeshki, S.R.; Hester, M.W.; Lin, Q. \& Nyman, J.A. 2000. The effects of oil spill and clean-up on dominant us gulf coast marsh macrophytes: a review. Environmental Pollution 108: 129-139.

Pilon-Smits, E. 2005. Phytoremediation. Annual Review of Plant Biology 56: $15-39$

Quiñones-Aguilar, E.; Ferrera-Cerrato, R.; Gavi-Reyes, F.; FernándezLinares, L.; Rodríguez-Vázquez, R. \& Alarcón, A. 2003. Emergencia y crecimiento de maíz en un suelo contaminado con petróleo crudo. Agrociencia 37: 585-594.

Racine, C.H. 1994. Long-term recovery of vegetation on two experimental crude oil spills in interior Alaska black spruce taiga. Canadian Journal of Botany 72: 1171-1177.

Roy, J.L.; McGill, W.B.; Lowen, H.A. \& Johnson, R.L. 2003. Relationship between water repellency and native and petroleum-derived organic carbon in soils. Journal Environmental Quality 32: 583-590.

Sass, J.E. 1951. Botanical microtechnique. Ames, Iowa State College Press.

Sefloral. 2001. http://www.sefloral.com.br/petrobras30.htm

Siciliano, S.D. \& Germida, J.J. 1999. Enhanced phytoremediation of chlorobenzoates in rhizosphere soil. Soil Biology and Biochemistry 31: $299-305$

Sifton, H.B. 1945. Air-space tissue in plants. Botanical Review 11: 108-143.

Singer, A.C.; Crowley, D.E. \& Thompson, I.P. 2003. Secondary plant metabolites in phytoremediation and biotransformation. Trends in Biotechnology 21: 123-130.

Smith, L.B.; Downs, J.; Klein, R.M. 1988. Euforbiáceas. In: Flora Ilustrada Catarinense. Herbário Barbosa Rodrigues. Itajaí, R. Reitz.

Tan, B.L.; Sarafis, V.; Beattie, G.A.C.; White, Itajaí R.; Darley, E.M. \& Spooner-Hart, R. 2005. Localization and movement of mineral oil in plants by fluorescence and confocal microscopy. Journal of Experimental Botany 56: 2755-2763.

Tesar, M.; Reichenauer, T.G. \& Sessitsch, A. 2002. Bacterial rhizosphere populations of black poplar and herbal plants to be used for phytoremediation of diesel fuel. Soil Biology \& Biochemistry 34: 1883-1892.

White, P.M.JR.; Wolf, D.C.; Thoma, G.J. \& Reunolds, C.M. 2006. Phytoremediation of alkylated polycyclic aromatic hydrocarbons in a crude oil-contamined soil. Water, Air, and Soil Pollution 169: $207-220$ 